\title{
Assessing preferences for improved smoking cessation medications: a discrete choice experiment
}

\author{
Joachim Marti
}

Received: 21 December 2009/Accepted: 7 June 2011/Published online: 26 June 2011

(C) Springer-Verlag 2011

\begin{abstract}
Background The use of smoking cessation medications can considerably enhance the long-term abstinence rate at a reasonable cost, but only a small proportion of quitters seek medical assistance. The objective of this study was to evaluate the factors that influence the decision to use such treatments and the willingness-to-pay of smokers for improved cessation drugs.

Method A discrete choice experiment was conducted amongst smokers in the French-speaking part of Switzerland. Choice sets consisted of two hypothetical medications described via five attributes (price, efficacy, possibility of minor side effects, attenuation of weight gain and availability) and an opt-out option. Various discrete choice models were estimated to analyse both the factors that influence treatment choice and those that influence the overall propensity to use a smoking cessation medication. Results Our results indicate that smokers are willing to pay for higher efficacy, less-frequent side effects and prevention of weight gain. Whether the drug is available overthe-counter or on medical prescription is of secondary importance. In addition, we show that there are several individual-specific factors influencing the decision to use such medications, including education level. Results also indicate substantial preference heterogeneity.

Conclusion This study shows that there is a potential demand for improved cessation medications. Broader

Electronic supplementary material The online version of this article (doi:10.1007/s10198-011-0333-z) contains supplementary material, which is available to authorized users.
\end{abstract}

J. Marti $(\bowtie)$

Faculty of Economics, Institute for Research in Economics,

University of Neuchâtel, 2000 Neuchâtel, Switzerland

e-mail: joachim.marti@unine.ch usage could be reached through lower out-of-pocket price and greater efficacy. Secondary aspects such as side effects and weight gain should also be taken into consideration.

Keywords Discrete choice experiments . Smoking cessation - Preference heterogeneity

JEL Classification I11 $\cdot \mathrm{I} 12 \cdot \mathrm{D} 12 \cdot \mathrm{C} 25$

\section{Introduction}

Smoking is the leading preventable cause of death in most developed countries. Switzerland is no exception, with more than nine thousand deaths attributable to tobacco use each year [1]. The proportion of daily or occasional smokers in the population between 14 and 65 years old was approximately $27 \%$ in 2009 [2], which is quite high in comparison with other developed countries. This high prevalence rate is partly due to permissive tobacco legislation. This was confirmed in a study by Joossens and Raw [3] grading the tobacco control intensity at the country level, in which Switzerland was ranked 18th amongst 30 European countries, mainly due to lack of restrictions and low prices. Switzerland is also home to several international tobacco companies that have substantial influence in political decisions.

A lower prevalence of smoking could be achieved by increasing the success rate of individuals who try to quit. Indeed, many smokers are motivated to quit and do make the attempt, ${ }^{1}$ but only a few succeed over the long term. One reason is that few seek assistance, even though the

\footnotetext{
${ }^{1}$ In 2007, 54 $\%$ of Swiss smokers wanted to quit, but only $10 \%$ within the next 30 days and $30 \%$ within the next 6 months [2].
} 
long-term abstinence rate can be considerably enhanced with appropriate cessation support. The estimated cold turkey (i.e., smoking cessation without assistance) quit rate is approximately $5 \%$, whilst a $10-20 \%$ long-term quit rate can be achieved with the most effective interventions [4]. Amongst the wide range of smoking cessation interventions, we distinguish non-pharmaceutical (medical counselling, group therapies, books, help line, acupuncture, etc.) from pharmaceutical (nicotine replacement therapies ${ }^{2}$ - or NRTs-and nicotine-free medications) ${ }^{3}$ treatments. The latter were found to be effective versus placebo in several randomised controlled trials [5].

This study focuses on nicotine-free smoking cessation medications, and its main objective is to assess smokers' preferences for such products. Our goal was threefold: to highlight the most important factors that influence the decision to use such treatment, to assess the value that smokers attach to attribute improvements, and to analyse preference heterogeneity. We used a discrete choice experiment (DCE) — a stated preferences (SP) techniquewhich consisted of presenting a sample of respondents with choices between several hypothetical treatments. The medications were described via five attributes (price, efficacy, side effects, effect on weight gain, and availability). The respondents were asked to choose several times between two alternative treatments and an opt-out option. We analysed choice data starting from the simple multinomial logit model (MNL) as the benchmark model. We then estimated more complex models that were able to take into account the specifics of the choice process and the panel structure of the data (i.e., each respondent makes several choices). Using the nested logit (NL) framework, we analysed both the influence of the product's characteristics on choice and the impact of individual characteristics on the propensity to use such medications. Then, random parameter logit (RPL) models allowed us to take unobserved heterogeneity into account.

The results consistently show that smokers value medications that have improved efficacy and less-frequent side effects and that prevent weight gain after cessation. In addition, we show that there are several individual factors that influence the decision to use such medications. We also show the importance to account for unobserved

\footnotetext{
${ }^{2}$ NRTs partially relieve the withdrawal symptoms that people experience when they quit, by compensating for the lack of nicotine in the organism. There are several NRTs currently available over-thecounter in Switzerland, including patches, gum, inhalers, lozenges and nasal sprays.

3 Two nicotine-free medications are available in Switzerland by medical prescription only (A list): bupropion (brand name Zyban ${ }^{\circledR}$ ), whose exact mode of action is still unclear [6], and varenicline (brand name Champix ${ }^{\circledR}$ ), which relieves symptoms of nicotine withdrawal and blocks the reinforcing effect of continued nicotine use through an antagonist and agonist action [7].
}

heterogeneity when analysing choice data. This information should help guide the efforts of smoking cessation actors (pharmaceutical industry, public health decision makers) to improve treatment acceptance and usage and thereby achieve higher cessation rates in the population.

\section{Related work}

Researchers have extensively applied DCE in the fields of marketing, transport and environmental economics. In health economics, the number of DCE studies has sharply increased during the past decade [8-12]. More specifically, many DCE applications have aimed to evaluate the health and non-health dimensions of medical treatments, for example: miscarriage management [13]; varicella vaccination [14]; insulin mixtures [15]; alcoholism medication [16]; colorectal cancer screening [17]; weight loss programmes [18]; knee injuries detection [19]; and lower urinary tract symptoms [20]. In Table 1, we provide a nonexhaustive list of empirical papers using DCE to value medical interventions along with the dimensions that were assessed.

Pharmaceutical smoking cessation treatments have been analysed from an economic point of view, especially with respect to cost-effectiveness [21-24], and all studies have concluded that these treatments lead to a low cost per life-year saved. In a cost-effectiveness study conducted in six western countries, Cornuz et al. [22] found a cost per life-year saved of US $\$ 792$ for a 45-year-old smoker using Zyban $^{\circledR}$ (bupropion) in Switzerland. Researchers have also examined the demand for smoking cessation therapies by focusing on various determinants. Tauras and Chaloupka [25] found that decreasing the price of NRTs would lead to an increase in sales of these products (estimated average price elasticity of -2.33 for patches and of -2.46 for gums). The effects of conversion to over-the-counter (OTC) status for nicotine patches and gums were analysed by Keeler et al. [26]. The authors estimated that after the conversion, the use of both therapies would increase substantially (78-92\% for patches and $180 \%$ for nicotine gum). Halpin et al. [27] investigated the demand of the general population for health insurance coverage extension to cover treatment for tobacco dependence, and they found that most people were willing to accept an increase of at least US \$3 in their basic health insurance premium to finance the coverage. Avery et al. [28] analysed the impact of smoking cessation product advertising on the purchasing of such products and on smoking behaviour. They found that the probabilities of attempting to quit and of quitting were positively associated with higher exposure to such advertising. 
Table 1 Published studies using DCE to value medical interventions

\begin{tabular}{|c|c|c|}
\hline Authors & Treatment & Dimension valued \\
\hline Ryan et al. [13] & Miscarriage management & Pain, time in hospital, time to return to normal activities, cost, complications \\
\hline Hall et al. [14] & Varicella vaccination & $\begin{array}{l}\text { Risk of mild side effects, risk of severe side effects, vaccine effectiveness, health } \\
\text { authority support, location for vaccination, price of vaccination }\end{array}$ \\
\hline Aristides et al. [15] & Insulin mixtures & $\begin{array}{l}\text { Timing of injection before meal, 2-h postprandial blood glucose, effect of prandial } \\
\text { dosing, nocturnal hypoglycaemic frequency }\end{array}$ \\
\hline Mark et al. [16] & Alcoholism medication & $\begin{array}{l}\% \text { of treated population who remained abstinent, } \% \text { of patients who had no incidence of } \\
\text { heavy drinking, } \% \text { of patients that experienced mild side effects, } \% \text { of patients who } \\
\text { complied at a high rate, mode of action, route of administration, price per day }\end{array}$ \\
\hline Marshall et al. [17] & Colorectal cancer screening & Process, preparation, pain, specificity, sensitivity \\
\hline Roux et al. [18] & Weight loss programmes & $\begin{array}{l}\text { Programme cost, travel time to programme, amount of doctor involvement, programme } \\
\text { components emphasised, focus of programme }\end{array}$ \\
\hline Bryan et al. [19] & Knee injury detection & $\begin{array}{l}\% \text { chance of requiring arthroscopy, time from initial consultation to end of treatment, \% } \\
\text { chance that knee problem is completely resolved, total cost to the patient }\end{array}$ \\
\hline Watson et al. [20] & Lower urinary tract symptoms & $\begin{array}{l}\text { Time to symptom improvement, treatment decreases prostate size, sexual side effects of } \\
\text { treatment, nonsexual side effects of treatment, treatment cost, } \% \text { chance of surgery }\end{array}$ \\
\hline
\end{tabular}

Two studies used stated preferences methods to investigate individual preferences for smoking cessation treatments. Busch et al. [29] applied contingent valuation (CV) to estimate willingness-to-pay (WTP) for medications that are more effective and that attenuate weight gain associated with smoking cessation. About $80 \%$ of the respondents were willing to pay for greater effectiveness, and twothirds of these individuals were willing to pay more if the treatment had an impact on weight gain. These authors also estimated that the mean WTP for a $100 \%$ effective treatment-i.e. the value of a statistical quit-was US \$538. The major limitation of $\mathrm{CV}$ is that it does not allow many dimensions of the good to be estimated at a time. The good has a value per se, and it is not possible to assess the relative importance of its dimensions. Paterson et al. [30] overcame this limitation by applying labelled ${ }^{4}$ DCE to the choice of smoking cessation therapies (nicotine gum, nicotine patch, nicotine inhaler and $\operatorname{Zyban}^{\circledR}$ ). They used cost, success rate and treatment length as variable attributes, with doses per day and availability as fixed characteristics. The flexibility of the model specifications they applied allowed the authors to investigate preference heterogeneity. They found that effectiveness was a primary consideration. Light and heavy smokers were both willing to pay substantial amounts for improved success rates (i.e., CAN $\$ 500$ and CAN \$300 to achieve a 40\% success rate).

We chose to use unlabelled choice experiments to focus on treatments' characteristics without connecting them to existing therapies. In addition to price and efficacy, we

\footnotetext{
${ }^{4}$ Also known as alternative-specific choice experiments. DCEs that use generic titles for the alternatives are called unlabelled DCEs, contrary to labelled choice experiments, where each alternative refers to a particular commodity (e.g., Zyban ${ }^{\circledR}$ ) [31].
}

focus on minor side effects, attenuation of weight gain and availability. We study preference heterogeneity by including individuals' characteristics in our modelling framework (1) as a part of the choice process and (2) directly through interactions with medication attributes. We also investigate unobserved heterogeneity by allowing tastes to vary across respondents using RPL models.

\section{Framework for analysis}

A majority of current smokers positively value the benefits associated with smoking cessation, resulting in a desire to quit and in frequent quit attempts. Most of these attempts are made cold turkey and thus have a relatively low longterm success rate. Relapses are frequent, particularly because of the significant costs associated with nicotine withdrawal. The use of a smoking cessation drug partially relieves the craving symptoms, resulting in increased success rates. The demand for such a product depends on the perceived additional net benefits it provides over alternative methods. For simplification purpose, we assume here that the only available alternative method is cold turkey cessation. Thus, in our analysis, we interpret opting out as the decision to use cold turkey cessation instead of a medication. The additional benefit of the treatment is the value the individual attaches to smoking cessation multiplied by the increased probability of successfully quitting that the treatment provides. ${ }^{5}$ The probability of long-term

\footnotetext{
5 The perceived value of quitting is defined as "the difference between the lifetime utility from quitting and the lifetime utility from continuing to smoke" (Avery et al. [28]).
} 
abstinence is negatively related to withdrawal symptoms. The medication precisely increases the success rate by decreasing these withdrawal symptoms. The benefits also include additional features of the medication, such as its ability to reduce weight gain associated with smoking cessation.

The benefits of the treatment are compared to its costs, which include both the out-of-pocket cost, and other non-monetary costs such as side effects, and time and effort to purchase the treatment, which is related to treatment availability. A smoker will decide to use a smoking cessation treatment when making a quit attempt if the perceived net benefits are positive. We expect potential quitters to positively value efficacy and the additional benefits of the medication, and to negatively value side effects and access costs.

\section{Materials and method}

The DCE method is based on the hypothesis that any good or service can be described as a set of characteristics or attributes. Consistent with Lancaster's theory of value [32], individuals do not appreciate commodities globally, but rather as a sum of attributes. In contrast to revealed preference techniques that analyse choices observed in reality, DCEs-as a stated preference technique-consist of presenting hypothetical choice situations ('choice sets', hereafter) to a sample of respondents. Each choice set contains two or more alternatives that vary according to the level of their attributes. It is assumed that individuals select the alternative from which they derive the highest utility. The probability of an alternative being chosen is then modelled in accordance with the random utility framework [33]. Applying appropriate econometric techniques to analyse observed decisions, the researcher is able to retrieve the indirect utility functions of individuals in the attribute-space.

The researcher is then able to estimate the relative importance of the attributes (marginal rates of substitution). When a monetary attribute is included, it is possible to estimate marginal willingness-to-pay (mWTP) for improvements in attributes and, by extension, global WTP for improved medications. Individual-specific characteristics that might influence the choice can also be included in the models. As mentioned by Ryan et al. [34], a complete DCE study is a complex process that involves three main steps prior to the econometric treatment: (1) definition of attributes and attribute levels; (2) experimental design and construction of choice sets and (3) data collection.

\section{Definition of attributes and attribute levels}

From existing literature, we initially developed a list of attributes about smoking cessation pharmaceutical treatments $[5,35,36]$ that seemed the most relevant to our research goals: price, efficacy, length of the treatment, possibility of minor side effects, attenuation of weight gain and availability. Meanwhile, we conducted two focus groups with five participants in order to identify important attributes and prevent the omission of salient ones. The length of the treatment was found to be of low importance and was therefore excluded.

The next step consisted of assigning levels to each attribute. The literature recommends that these should be realistic, well-defined, plausible and should potentially involve trade-offs [34]. The first three attributes describe continuous dimensions, whereas the latter two are dichotomous. Levels for price were defined on the basis of true market prices. For instance, the out-of-pocket cost of a comprehensive treatment course with Zyban ${ }^{\circledR}$ (bupropion) is about CHF 300 [6]. A central advantage of DCE is that it allows larger attribute variability. The price attribute was therefore described with four possible levels within a plausible interval (CHF 200-CHF 500).

We can express long-term efficacy in an absolute or relative way. Many studies report the efficacy of a medication relative to a placebo or relative to an alternative treatment in terms of odds ratios [5], whilst evaluations of absolute long-term abstinence rate are also possible [4]. Because it is difficult for respondents to interpret odds ratios, we chose to use the following definition of efficacy: the proportion of quitters who still do not smoke 1 year after treatment. The quit rate at 1 year is approximately $5 \%$ for smokers without assistance [4], 15\% for those with bupropion and $22 \%$ for those with varenicline (Gonzales et al. [7]; Jorenby et al. [37]). Selected levels for the

Table 2 Attributes and levels

\begin{tabular}{lll}
\hline Attributes & Levels & Opt out \\
\hline Price: price for the complete treatment (PRICE) & CHF 200, CHF 300, CHF 400, CHF 500 & CHF 0 \\
Efficacy: abstinence rate at 1 year (EFF) & $15,25,40,50 \%$ & $5 \%$ \\
Side effects: risk of benign side effects (SIDEF) & $10,30,50 \%$ & $0 \%$ \\
Attenuation of weight gain associated with smoking cessation & Yes, no & No \\
(WEIGHT) & & Over-the-counter (not restricted), medical prescription \\
Availability (AVAIL) & Not restricted \\
\hline
\end{tabular}


medications were $15 \%$ (close to bupropion), $25 \%$ (close to varenicline), $40 \%$ and $50 \%$ (improved efficacy). The most commonly reported benign side effects of bupropion and varenicline are insomnia, nausea and dry mouth [4, 7, 38], and these are quite frequent (30\% for bupropion and $50 \%$ for varenicline). In addition to these two side-effect levels, we chose a third $(10 \%)$ to depict an improved medication. Weight gain is strongly associated with smoking cessation, with the average gain after cessation reaching approximately 4-5 kg (Froom et al. [39], Klesges et al. [40]; Williamson et al. [41]). Some smokers are discouraged from cessation because of this tendency. An improved medication could include components that prevent weight gain (Meyers et al. [42]). Finally, medications are either available over-the-counter or are obtainable only with a medical prescription. All the attributes and their respective levels are presented in Table 2. The table also shows the levels assumed for the opt-out option (baseline levels).

\section{Experimental design}

Choice sets presented to respondents contained two unlabelled alternatives ('medication A' and 'medication B'). Because our target population had not necessarily decided to use such a medication at the time of the study, we also included an opt-out option to allow individuals to be nondemanders [43]. With two four-level attributes, one threelevel attribute and two dichotomous attributes, the full factorial design gives rise to $192\left(4^{2} \times 3 \times 2^{2}\right)$ possible hypothetical medications. We used a fractional factorial design in order to reduce the possible combinations. Choice sets were generated starting from a resolution 3 orthogonal array obtained on Sloane's website [44] and using the method proposed by Street and Burgess [45]. We obtained an orthogonal main effects plan (OMEP), whose efficiency compared with an optimal design is $96.04 \%$ [46]. The design produced 16 distinct choice sets that were divided into 2 blocks of 8 choice sets [31]. Each respondent was then assigned randomly to any of the two blocks.

To verify the consistency of responses, it is customary to add constructed scenarios to the main design. Thus, we created two additional choice sets containing a dominant alternative. Dominance is achieved when one alternative is superior for at least one attribute whilst the other attributes are at the same level. ${ }^{6}$ Respondents are supposed to choose the dominant (or the opt out) alternative if rationality holds. In summary, we presented ten choice sets to each respondent, two of which were consistency checks [47, 48].

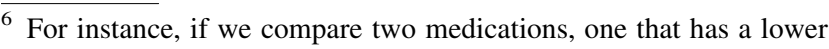
price, higher efficacy and fewer side-effects, with the other attributes being at the same level, is considered dominant.
}

Questionnaire and data collection

The questionnaire was first pre-tested in a sample of 25 respondents to collect comments, suggestions and personal evaluations of the task difficulty, giving rise to the final version of the questionnaire. Then, two hundred and thirty subjects were recruited from the French-speaking part of Switzerland. The main inclusion criteria were age between 15 and 64 years and being a daily or occasional smoker. The respondents also had to express an interest in quitting smoking. The sample was representative of the Frenchspeaking Swiss population of smokers with respect to age, gender and education level. The questionnaire was divided into two parts: the choice experiments and the collection of individual information. In the DCE part, respondents were asked to imagine the following scenario (in brief):

"You have decided to quit smoking, and you have the possibility to be supported by a smoking cessation medication that can improve your chance of quitting (without any help, the success rate at 1 year is 5\%) ... You will be presented with 10 situations in which two medications are described. Please choose, for each situation, if you would buy medication A, medication B or neither".

We then gave a detailed description of each attribute and presented their respective levels. The same information was also provided in the presentation of each choice set, an example of which is shown in 'Appendix'. In the second part of the questionnaire, we gathered information about smoking history, quitting history, health status and demographics.

\section{Econometric analysis}

Discrete choice modelling relies on the random utility theory [33], where the utility that individuals derive from an alternative is divided into two components: a systematic (observable) and a stochastic (unobservable) one. It is assumed that the former depends linearly on attribute levels whilst the latter is due to unobserved information and measurement errors. More formally, we denote the utility that individual $i$ derives from alternative $j$ by:

$U_{i j}=V_{i j}+\varepsilon_{i j}$,

Where $V_{i j}$ is the observable component and $\varepsilon_{i j}$ the random error. With $k$ attributes, assuming a linear utility function, we have the following functional form:

$V_{i j}=\beta_{1} X_{i j 1}+\beta_{2} X_{i j 2}+\cdots+\beta_{k} X_{i j k}=\boldsymbol{X}_{i j}^{\prime} \boldsymbol{\beta}$.

Under the assumption of rationality, individuals choose the alternative from which the utility derived is the highest. Therefore, alternative $j$ will be chosen over alternative $q$ if 


$$
U_{i j}>U_{i q} .
$$

From this, we derive the probability that individual $i$ chooses alternative $j$ amongst $p$ alternatives:

$P_{i j}=\operatorname{Prob}\left(V_{i j}+\varepsilon_{i j}>V_{i p}+\varepsilon_{i p} \forall p \neq j\right)$.

Identically,

$P_{i j}=\operatorname{Prob}\left(V_{i j}-V_{i p}>\varepsilon_{i p}-\varepsilon_{i j} \forall p \neq j\right)$.

The resulting choice model depends on the assumption made about the distribution and the correlation structure of the error term. Below, we describe three choice models that differ in their complexity: the multinomial logit model $(\mathrm{MNL})$, the nested logit model (NL) and the random parameter logit model (RPL).

\section{Multinomial logit}

If we assume that the errors are independent and identically distributed (IID) Type I Extreme Value, we obtain the standard multinomial logit (MNL) specification. After some algebraic manipulations (see McFadden [49] or Train [50] for details), we obtain the following expression for the choice probabilities:

$P_{i j}=\frac{\exp \left(\boldsymbol{X}_{i j}^{\prime} \boldsymbol{\beta}\right)}{\sum_{p} \exp \left(\boldsymbol{X}_{i p}^{\prime} \boldsymbol{\beta}\right)}$

The IID assumption induces the independence from irrelevant alternatives (IIA) axiom, which means that the relative probability of choosing one alternative over another is unaffected by the presence of additional alternatives in the choice set [51]. In other words, the IIA property implies that all alternatives are perfect substitutes. In this case, the choice sets included three alternatives (medication A, medication B and the opt-out option). If IIA holds, this would mean that, for example, an improvement in medication $A$ would lead to proportionate decreases in the frequencies at which medication B and opting out are chosen. Here, it is likely that an improvement in medication A would produce a larger decrease in the probability of choosing medication B than of choosing the opt-out option. Another limitation of the simple MNL specification is that it does not take into account the fact that each respondent faces several choice situations and that there might be correlation across choice sets faced by a single individual. To handle these limitations, we estimated two additional models allowing for more complex substitution patterns and for possible correlation across choice situations.

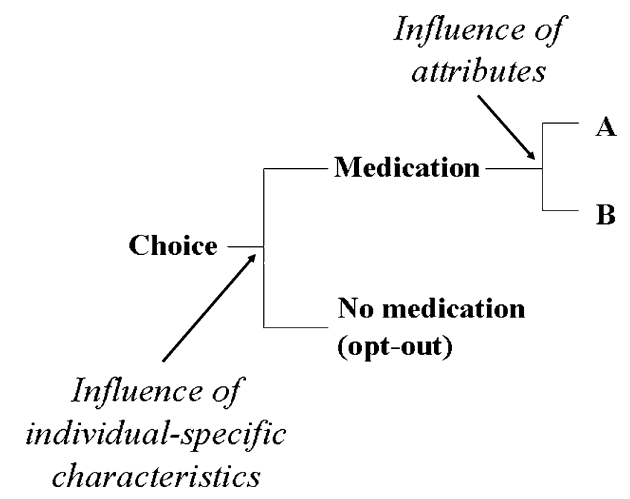

Fig. 1 Nested logit structure

Nested logit

In this specification, similar alternatives are partitioned into subsets called nests. For any two alternatives (say, $a$ and $b$ ) in the same nest, $\varepsilon_{a}$ is correlated with $\varepsilon_{b}$, whereas for any two alternatives in different nests, the unobserved portion of utility is uncorrelated. ${ }^{7}$ In our case, the first nest holds the medications (A and B), whilst the second nest contains only the opt-out option. For clarity, we can visualise each choice as the result of two decisions. First, individuals decide whether or not to opt out. Then, conditional on not having chosen the opt-out option, they choose a medication according to the attribute levels. A suitable way to illustrate the model structure is with a tree diagram (Fig. 1). The 'branches' denote the alternative subsets within which IIA holds, and the 'leaves' are the alternatives.

The probability that individual $i$ chooses alternative $j$ within nest $n$ (which contains $J_{n}$ alternatives) can be depicted as the product of two probabilities [33]: the probability of choosing nest $n$ amongst $N$ nests and the conditional probability of alternative $j$ being chosen (given that nest $n$ is chosen):

$P_{i j n}=P_{\text {nest } n} \cdot P_{j \mid \text { nest } n}$

with

$P_{\text {nest } n}=\frac{e^{z_{n}^{\prime} \gamma+\tau_{n} \mathrm{I} \mathrm{V}_{n}}}{\sum_{n=1}^{N} e^{z_{n}^{\prime} \gamma+\tau_{n} \mathrm{I} \mathrm{V}_{n}}}$

and

$P_{j \mid \text { nest } n}=\frac{e^{x_{j \mid n}^{\prime} \beta}}{\sum_{j=1}^{J_{n}} e^{x_{j \mid n}^{\prime} \beta}}$,

where $z$ is a vector of individual-specific characteristics, $x$ is a vector of medication attributes, $\gamma$ and $\beta$ are vectors of parameters, and IV is the so-called inclusive value with its

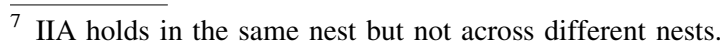


associated inclusive value parameter $\tau$ [50]. The inclusive value (IV) parameter is an indicator of the degree of substitutability between the alternatives. When it equals one, all alternatives are perfectly substitutable. In this case, the model collapses to the simple multinomial logit model (MNL), and there is no need to use a more flexible specification. If the IV parameter equals zero, this means that the choice amongst nests is completely independent of the choice amongst the alternatives. In such a case, one independent choice model per decision can be estimated. The use of the NL specification is appropriate when the IV parameter lies between zero and one because this means that alternatives within a nest are closer substitutes for each other than for alternatives in other nests [50].

\section{Random parameter logit}

The random parameter logit model (RPL), also referred as mixed logit, allows for more flexible substitution patterns and takes into account the influence of unobserved individual characteristics on choices. In this framework, the choice probability is a weighted average of the multinomial logit choice probabilities, where the weights are the possible values of $\beta$. The researcher must then specify a distribution for the coefficients with parameters $\theta$, i.e., $f(\beta \mid \theta)$ :

$P_{i j}=\int\left(\frac{\exp \left(\boldsymbol{X}_{i j}^{\prime} \boldsymbol{\beta}\right)}{\sum_{p} \exp \left(\boldsymbol{X}_{i p}^{\prime} \boldsymbol{\beta}\right)}\right) f(\beta \mid \theta) d \beta$

Most commonly, it is assumed that the $\beta$ 's are normally distributed. The log-normal distribution is also often used, in particular for the coefficients that are assumed to be strictly positive. We can interpret the RPL model as a model in which the parameters are randomly distributed across individuals. The utility of the $j$-th alternative for an individual $i$ can be written as:

$U_{i j}=X_{i j}^{\prime} \beta_{i}+\varepsilon_{i j}$

where the $\beta_{i}$ 's are the random coefficients that we can decompose into two parts, as follows:

$\beta_{i}=\bar{\beta}+\eta_{i}$

where $\bar{\beta}$ is the population mean and $\eta_{i}$ is a stochastic deviation representing preference heterogeneity. Rewriting the model, we obtain:

$U_{i j}=X_{i j}^{\prime} \bar{\beta}+X_{i j}^{\prime} \eta_{i}+\varepsilon_{i j}$

The stochastic portion of utility (i.e., $X_{i j}^{\prime} \eta_{i}+\varepsilon_{i j}$ ) is correlated across choice situations due to the common influence of $\eta_{i}$. Since the integral in (10) has no closed-form, simulation is used to estimate the parameters. ${ }^{8}$

Model specification

In all the models, the choice amongst alternatives depends on the five attributes: price (Price), efficacy (Eff), side effects (Side), effect on weight gain (Weight) and availability (Avail), all as defined above in Table 2. The utility function is simply:

$$
\begin{aligned}
U_{i j}= & \beta_{1} \text { Price }_{i j}+\beta_{2} \text { Eff }_{i j}+\beta_{3} \text { Side }_{i j}+\beta_{4} \text { Weight }_{i j} \\
& +\beta_{5} \text { Avail }_{i j}+\varepsilon_{i j} .
\end{aligned}
$$

In addition, in the NL model, the opt-out decision is assumed to depend on a series of individual-specific characteristics and on the attributes [see (8)]. Individual-specific variables include the number of years the respondent has smoked (Years_sm), the previous use of any smoking cessation help (Help), gender (Gender), whether the respondent is anxious (Anx), educational level (Sec and Sup), and the presence of any children in the household (Child).

In the RPL model, the parameters were assumed to be normally distributed in the basic specification:

$$
\begin{aligned}
U_{i j}= & \beta_{1 i} \text { Price }_{i j}+\beta_{2 i} \text { Eff }_{i j}+\beta_{3 i} \text { Side }_{i j}+\beta_{4 i} \text { Weight }_{i j} \\
& +\beta_{5 i} \text { Avail }_{i j}+\varepsilon_{i j}
\end{aligned}
$$

with $\beta_{k i} \sim N\left(\beta_{k}, \sigma_{k}\right)$. We also estimated models in which coefficients of Price and Eff where assumed to be lognormally distributed (price was then entered negatively in the specification).

To go further into the investigation of preference heterogeneity, we estimated models that include interaction terms between individual-specific characteristics and some attributes, as suggested by Ryan et al. [52]. We created an interaction between price and indicators corresponding to three levels of monthly income, i.e. Price $\times \mathrm{Inc}_{1}$, Price $\times \mathrm{Inc}_{2}$, and Price $\times \mathrm{Inc}_{3}$, where $\mathrm{Inc}_{\mathrm{i}}$ is an indicator for the $i$-th of the following income groups: $<\mathrm{CHF} 4,500, \mathrm{CHF}$ 4,500-8,500 and >8,500 CHF. We created an additional interaction term between body mass index and the attribute Weight, using two subgroups ( $\mathrm{Bmi}_{1}$ : up to $25 \mathrm{~kg} / \mathrm{m}^{2}$ and $\mathrm{Bmi}_{2}$ : over $25 \mathrm{~kg} / \mathrm{m}^{2}$ ). The general form of the utility function including interaction terms was:

$$
\begin{aligned}
U_{i j}= & \delta_{1} \text { Price }_{i j}+\delta_{2}\left(\text { Price } \times \mathrm{Inc}_{2}\right)_{i j}+\delta_{3}\left(\text { Price } \times \mathrm{Inc}_{3}\right)_{i j} \\
& +\delta_{4} \text { Eff }_{i j}+\delta_{5} \text { Side }_{i j}+\delta_{6} \text { Weight }_{i j} \\
& +\delta_{7}\left(\text { Weight } \times \text { Bmi }_{2}\right)_{i j}+\delta_{8} \text { Avail }_{i j}+\varepsilon_{i j}
\end{aligned}
$$

Because individuals with higher income are supposed to

\footnotetext{
${ }^{8}$ In short, draws from $f(\beta \mid \theta)$ are used to get a simulated value of the $\log$-likelihood function. This is done for different values of $\theta$, until we obtain the maximum simulated likelihood (Train [50]).
} 
Table 3 Descriptive statistics $(N=131)$

\begin{tabular}{|c|c|c|c|}
\hline Variable & Definition & Mean & Std. dev. \\
\hline \multicolumn{4}{|l|}{ Smoking history } \\
\hline Years_sm & Number of years smoking & 19.9 & \multirow[t]{4}{*}{11.88} \\
\hline Lowdep & $=1$ if FTND score $<4$ & 0.67 & \\
\hline Middep & $=1$ if FTND is between 4 and 7 & 0.29 & \\
\hline Highdep & $=1$ if FTND $>7$ & 0.04 & \\
\hline \multicolumn{4}{|c|}{ Smoking cessation } \\
\hline Help & $=1$ if have ever used NRT or Zyban & 0.23 & \multirow[t]{4}{*}{2.50} \\
\hline Attempts & Number of previous quit attempts & 2.72 & \\
\hline Ability & $=1$ if confident about ability to quit & 0.67 & \\
\hline Quit 6 months & $=1$ if plans to quit within the next 6 months & 0.24 & \\
\hline \multicolumn{4}{|l|}{ Health state } \\
\hline Health & $=1$ if feels in excellent health & 0.22 & \multirow[t]{3}{*}{3.29} \\
\hline Bmi & Respondent's body mass index & 23.9 & \\
\hline Anx & $=1$ if very anxious & 0.08 & \\
\hline \multicolumn{4}{|c|}{ Household characteristics } \\
\hline Hhinc & Household monthly income (CHF) & $6,393.1$ & \multirow[t]{2}{*}{3,021} \\
\hline Child & $=1$ if there are any children & 0.35 & \\
\hline \multicolumn{4}{|c|}{ Respondent's characteristics } \\
\hline Gender & $=1$ if resp. is a male & 0.56 & \multirow[t]{5}{*}{12.13} \\
\hline Age & Age in years & 38.7 & \\
\hline Prim & $=1$ if primary education & 0.21 & \\
\hline $\mathrm{Sec}$ & $=1$ if secondary education & 0.57 & \\
\hline Sup & $=1$ if higher education & 0.22 & \\
\hline
\end{tabular}

have a lower marginal valuation of money, we expect $\delta_{2}$ and $\delta_{3}$ to be positive (leading to a smaller negative impact of price on utility in these income groups). We also assume that individuals with BMI over 25 attach a higher value to the weight attribute, i.e., that $\delta_{7}$ is positive.

\section{Results}

\section{Descriptive statistics}

Between March and April 2008, 230 paper-and-pencil questionnaires were mailed. A response rate of $60 \%$ was achieved (138 surveys collected). We excluded five respondents due to missing data, making the total number of valid questionnaires 133 (69 from the first block and 64 from the second block). Only two individuals failed the dominance test, i.e., chose the non-dominant alternative. We excluded them from the sample, resulting in 131 individuals who were used for the model estimations (yielding 1,048 observations). Amongst the 1,048 $(131 \times 8)$ choice responses, the opt-out option was selected 491 times $(46.9 \%)$. In the sample, 24 individuals always chose the opt-out option (no treatment). This subgroup is defined as serial non-participants [53]. Some authors suggest dropping these individuals from the sample to carry out the estimations, because some of these individuals are likely to opt out as a way of protesting. Deleting these responses can lead to inconsistent estimates, and the nested logit structure used here allows us to explain the factors that influence non-participation; therefore, we did not drop these respondents.

Table 3 summarises statistics about smoking and quitting history, health status and socio-economic characteristics. The mean age of the sample is 38.8 years; the distribution amongst the different age groups is close to the distribution in the French-speaking Swiss population of smokers. Respondents with higher education levels were slightly overrepresented, to the detriment of the population with only secondary education. Only five respondents had a Fagerström Test for Nicotine Dependence (FTND) score over seven. On average, the respondents had smoked for 20 years, and two-thirds of them had already tried to quit at least once for at least 2 weeks. Amongst these unsuccessful quitters, the mean number of quit attempts was 2.63 (std.dev. 2.52), and $23 \%$ of the individuals had already used a pharmaceutical smoking cessation therapy, mostly NRT. A large majority of the respondents (67\%) were confident about their ability to quit, although only $24 \%$ were actually planning to quit within the next 6 months. 
The results from the MNL and NL models are presented in Table 4, results from the RPL models are in Table 5, and results of the models that include interactions are presented in Table 6. All estimations were performed using Stata version 10.0 (Stata Corp., Texas, USA). In all models, the coefficients of the utility function are highly significant and of the expected sign except for availability, which is significant only in one of the RPL models (Model 5). First, focusing on the results of the simple MNL model (Model 1 ), we observe that higher price and a higher prevalence of side effects both give rise to lower utility whilst long-term efficacy is positively valued. An interesting result is the considerable importance that potential quitters attach to the presence of an effect on weight gain. However, the relative importance of this characteristic might be biased upwards because the attribute is presented as a dichotomous (yes/ no) option whilst price, efficacy and side effects are presented in percentage. ${ }^{9}$ The two additional MNL models include an alternative-specific constant (ASC) for the optout option, as a fixed effect in Model 2, and as a random effect in Model 3. The ASC is significant and positive in both cases, indicating a propensity to choose the opt-out option, even after accounting for differences in attributes. This suggests the presence of an opt-out bias amongst respondents that might reflect the fact that respondents opt out because decisions are hard to make. We investigated this issue in comparing opt-out rates across choice sets, and we do not find evidence of higher opt-out rates in choice sets with more similar alternatives. Another possible interpretation is that the benefits of the presented alternatives rarely outweigh the observed and unobserved costs of using a medication.

In the first column of Table 4, we provide the results of the Hausman-McFadden test [54], which tests the IIA assumption. The procedure consists of re-estimating the model based on a subset of alternatives. If IIA holds, the parameters in both models should be the same. The Hausman-McFadden statistic tests the equality of the parameters, and its associated statistic is assumed to follow a Chi-square distribution. The high value of the Chi-square statistic indicates that the assumption of IIA (and thus, the MNL model) is not sustainable in this choice context $(P<0.05)$. This result supports the use of a more flexible specification. Looking at the NL specification (Model 4), we notice that the IV parameter associated with the treatment branch is significant and lies between zero and one, ${ }^{10}$ indicating that the separation of alternatives into nests is

\footnotetext{
9 In order to assess potential non-linearity within these attributes, a MNL model was also estimated using the levels of the attributes in the utility function (the levels were effects coded [31]). Results, available upon request, show that the linearity assumption is reasonable.

10 The IV parameter associated with the opt-out option was set to one.
}

appropriate. Then, we focus on the second part of the NL model (opt-out decision). Because we modelled the probability of opting out, a negative significant coefficient associated with a variable means that an increase of that variable decreases the probability of opting out (or, similarly, increases the probability of choosing a medication). This is the case for the variable child $(P<0.05)$; individuals who have children are less likely to opt out. An explanation would be that those individuals are more motivated to quit because they include their children's future health status in their decision process. The coefficient for higher education is also significant and negative $(P<0.01)$, the reference category being primary education. This could denote better perception and understanding of the potential benefits of smoking cessation amongst more educated individuals. By contrast, two variables have a positive and significant coefficient. Smokers who have smoked for a greater number of years are more likely to opt out $(P<0.05)$. This result is difficult to explain because these individuals are more strongly addicted and thus should benefit more from a medication that relieves withdrawal symptoms. Possible explanations could be that long-term smokers are simply reluctant to use drugs to handle their smoking habit, that they are overconfident about their future ability to quit, or that their perceived benefits of cessation are low. Anxiety has a positive impact on opting out $(P<0.01)$. This could reflect lower perceived benefits of cessation amongst anxious individuals because of a stronger psychological addiction.

The estimation results of the RPL models are presented in Table 5. In Models 5 and 6, all coefficients are assumed to be normally distributed whilst in Models 7 and 8, the coefficients for Price and Eff are assumed to follow a log-normal distribution. Unlike in previous models, the coefficient associated with availability is positive and significant $(P<0.05)$, but only in Model 5. This result provides some evidence that individuals would positively value a switch to 'OTC status' for these drugs. Because we have random coefficients, we also provide estimates of the associated standard deviations. Their significance (except for Avail) indicates the presence of preference heterogeneity. Taking this heterogeneity and possible correlation across choices into account seems to bring significant improvements in terms of goodness-of-fit. Model 6 is the preferred specification regarding the log-likelihood, and both the AIC and BIC criteria. Models that include interactions between the price attribute and income and between the weight attribute and BMI are presented in Table 6 . The results consistently show that the relative importance of the price attribute is lower for individuals with higher income. Moreover, we see that overweight individuals $(\mathrm{BMI}>25)$ value the fact that a treatment prevents weight gain more highly, but not significantly. 
Table 4 Estimation results-MNL and NL models

\begin{tabular}{|c|c|c|c|c|}
\hline Utility function & $\begin{array}{l}\text { MNL } \\
\text { Model } 1\end{array}$ & $\begin{array}{l}\text { MNL } \\
\text { Model } 2\end{array}$ & $\begin{array}{l}\text { MNL } \\
\text { Model } 3\end{array}$ & $\begin{array}{l}\text { NL } \\
\text { Model } 4\end{array}$ \\
\hline Opt-out ASC (fixed) & - & $\begin{array}{l}0.6289 * * \\
(0.2637)\end{array}$ & - & - \\
\hline Opt-out ASC(random) & - & - & $\begin{array}{l}0.6675^{*} \\
(0.4018) \\
{[2.78 * * *]}\end{array}$ & - \\
\hline Price & $\begin{array}{l}-0.0044 * * * \\
(0.0004)\end{array}$ & $\begin{array}{l}-0.0036^{* * *} \\
(0.0005)\end{array}$ & $\begin{array}{l}- \\
0.0051 * * * \\
(0.0007)\end{array}$ & $\begin{array}{l}- \\
0.0033 * * * \\
(0.0005)\end{array}$ \\
\hline Eff & $\begin{array}{l}0.0543 * * * \\
(0.0038)\end{array}$ & $\begin{array}{l}0.0590 * * * \\
(0.0044)\end{array}$ & $\begin{array}{l}0.0821 * * * \\
(0.0062)\end{array}$ & $\begin{array}{l}0.0434 * * * \\
(0.0057)\end{array}$ \\
\hline Side & $\begin{array}{l}-0.0358 * * * \\
(0.0032)\end{array}$ & $\begin{array}{l}-0.0320 * * * \\
(0.0036)\end{array}$ & $\begin{array}{l}- \\
0.0377 * * * \\
(0.0042)\end{array}$ & $\begin{array}{l}- \\
0.0266 * * * \\
(0.0047)\end{array}$ \\
\hline Weight & $\begin{array}{l}0.7545 * * * \\
(0.1055)\end{array}$ & $\begin{array}{l}0.7653 * * * \\
(0.1085)\end{array}$ & $\begin{array}{l}0.9347 * * * \\
(0.1235)\end{array}$ & $\begin{array}{l}0.5610^{* * *} \\
(0.1103)\end{array}$ \\
\hline Avail & $\begin{array}{l}0.0124 \\
(0.0933)\end{array}$ & $\begin{array}{l}0.0970 \\
(0.1022)\end{array}$ & $\begin{array}{l}0.0312 \\
(0.1169)\end{array}$ & $\begin{array}{l}0.0004 \\
(0.0733)\end{array}$ \\
\hline \multicolumn{5}{|l|}{ Opt-out choice (NL only) } \\
\hline Years_sm & & & & $\begin{array}{l}0.0126 * * \\
(0.0052)\end{array}$ \\
\hline Help & & & & $\begin{array}{l}-0.1243 \\
(0.1456)\end{array}$ \\
\hline Gender & & & & $\begin{array}{l}-0.0316 \\
(0.1292)\end{array}$ \\
\hline Anx & & & & $\begin{array}{l}0.6767 * * * \\
(0.2538)\end{array}$ \\
\hline $\mathrm{Sec}$ & & & & $\begin{array}{l}0.0051 \\
(0.1479)\end{array}$ \\
\hline Sup & & & & $\begin{array}{l}- \\
0.5852 * * * \\
(0.1882)\end{array}$ \\
\hline Child & & & & $\begin{array}{l}-0.3159^{* *} \\
(0.1374)\end{array}$ \\
\hline IV parameter & & & & $\begin{array}{l}0.6698 * * * \\
(0.1136)\end{array}$ \\
\hline \multicolumn{5}{|l|}{ IIA test } \\
\hline $\begin{array}{l}\text { Hausma-McFadden } \\
\mathrm{Chi}^{2} \\
(P \text { value })\end{array}$ & $\begin{array}{l}6.40 \\
(0.011)\end{array}$ & & & \\
\hline $\mathrm{N}$ & 1,048 & 1,048 & 1,048 & 1,048 \\
\hline AIC & $1,904.4$ & $1,900.6$ & $1,520.5$ & $1,884.8$ \\
\hline $\mathrm{BIC}$ & $1,934.8$ & $1,937.0$ & $1,563.0$ & $1,975.9$ \\
\hline 11 & -947.2 & -944.3 & -753.2 & -927.4 \\
\hline
\end{tabular}

In the MNL models, the opt-out option is defined with specific values for the attributes. In the NL model, the opt-out option has no associated attribute value. Standard errors in parentheses. Standard deviation of random coefficients in brackets

* Significant at $10 \%$

** Significant at $5 \%$

*** Significant at $1 \%$ 
Table 5 Estimation results-RPL models

\begin{tabular}{|c|c|c|c|c|}
\hline Utility function & Model 5 & Model 6 & Model 7 & Model 8 \\
\hline \multirow[t]{3}{*}{ Opt-out ASC } & - & 0.4534 & - & 0.5903 \\
\hline & & $(0.4198)$ & & $(0.4407)$ \\
\hline & & {$[2.5180 * * *]$} & & {$[2.9714 * * *]$} \\
\hline \multirow[t]{3}{*}{ Price } & $-0.0095^{* * *}$ & $-0.0074 * * *$ & $-0.0093 * * *$ & $-0.0082 * * *$ \\
\hline & $(0.0011)$ & $(0.0010)$ & $(0.0012)$ & $(0.0011)$ \\
\hline & {$[0.0078 * * *]$} & {$[0.0040 * * *]$} & {$[0.0111 * * *]$} & {$[0.0069 * * *]$} \\
\hline \multirow[t]{3}{*}{ Eff } & $0.1033 * * *$ & $0.1086^{* * *}$ & $0.1026^{* * *}$ & $0.1113 * * *$ \\
\hline & $(0.0092)$ & $(0.0104)$ & $(0.0091)$ & $(0.0090)$ \\
\hline & {$[0.0553 * * *]$} & {$\left[0.0665^{* * *}\right]$} & {$[0.0532 * * *]$} & {$[0.0516 * * *]$} \\
\hline \multirow[t]{3}{*}{ Side } & $-0.0694 * * *$ & $-0.0662 * * *$ & $-0.0583 * * *$ & $-0.0564 * * *$ \\
\hline & $(0.0077)$ & $(0.0080)$ & $(0.0080)$ & $(0.0070)$ \\
\hline & {$[0.0562 * * *]$} & {$[0.0511 * * *]$} & {$[0.0515 * * *]$} & {$[0.0352 * * *]$} \\
\hline \multirow[t]{3}{*}{ Weight } & $1.3851 * * *$ & $1.2978 * * *$ & $1.1942 * * *$ & $1.1317 * * *$ \\
\hline & $(0.2274)$ & $(0.2103)$ & $(0.1980)$ & $(0.1904)$ \\
\hline & {$[1.9810 * * *]$} & {$[1.6125 * * *]$} & {$[1.2652 * * *]$} & {$[1.3486 * * *]$} \\
\hline \multirow[t]{3}{*}{ Avail } & $0.3104 * *$ & 0.2261 & 0.2050 & 0.1367 \\
\hline & $(0.1416)$ & $(0.1573)$ & $(0.1298)$ & $(0.1426)$ \\
\hline & [0.1186] & [0.2147] & [0.0082] & {$[0.2086]$} \\
\hline $\mathrm{N}$ & 1,048 & 1,048 & 1,048 & 1,048 \\
\hline AIC & $1,463.3$ & $1,442.6$ & $1,473.7$ & $1,451.7$ \\
\hline $\mathrm{BIC}$ & $1,524.0$ & $1,515.6$ & $1,534.5$ & $1,524.6$ \\
\hline 11 & -721.6 & -709.3 & -726.9 & -713.9 \\
\hline
\end{tabular}

In the models, the opt-out option is defined with specific values for the attributes. In Models 5 and 6 , all coefficients are normally distributed. In Models 7 and 8, the coefficients for Price and Eff are log-normally distributed; all other coefficients are normally distributed. Thus, in Models 7 and 8, the parameters for Price and Eff are the means and std. dev. of the coefficients derived from the mean and std. dev. of the logarithm of the coefficients (see e.g., Train [50] for the appropriate transformation). Standard errors in parentheses. Standard deviation of random coefficients in brackets

* Significant at $10 \%$

** Significant at $5 \%$

*** Significant at $1 \%$

\section{Welfare measures}

The ratio between any two coefficients in (14), (15) or (16) allows us to quantify the relative importance of the corresponding attributes, i.e., the marginal rate of substitution between them. If the price coefficient is included as the denominator, we obtain a marginal willingness-to-pay (mWTP) for the variation of an attribute. For example, we can value the improvement of the efficacy of a treatment by computing $-\left(\beta_{2} / \beta_{1}\right)$ ceteris paribus, i.e., the WTP for a 1-percentage-point increase in efficacy.

To compute mWTP estimates, we rely on the coefficients of the models without interactions (specifically, we rely on estimates from Models 1, 3, 4 and 6). Dividing the estimated coefficients of non-monetary attributes by the negative of the price coefficient gives rise to mWTP estimates. These are presented in Table 7. As suggested by Hole, we applied the Krinsky-Robb method to compute confidence intervals $[55,56] .{ }^{11}$ Table 8 presents the mWTP estimated from the models with interactions.

Making some simple computations, one can derive from the estimated WTP the incremental value of an improved smoking cessation medication over cold-turkey cessation. Using WTP estimates from the preferred specification (Model 6) and assuming a linear relationship between WTP and increased efficacy and between WTP and the prevalence of minor side effects, we compare cold turkey cessation with a hypothetical medication that has the

\footnotetext{
11 This method, which is also referred to as parametric bootstrap, consists of taking draws from a multivariate normal distribution with means and covariance given by the estimated coefficients and the associated variance-covariance matrix. Here, we performed 10,000 draws to obtain 10,000 values of the coefficients from the joint distribution. We used these values to compute $10,000 \mathrm{mWTP}$ estimates for each non-price attribute. The $95 \%$ confidence interval is then defined by taking the upper and lower 2.5 percentiles of the distribution.
} 
Table 6 Estimation results-models with interactions

\begin{tabular}{|c|c|c|c|}
\hline Utility function & $\begin{array}{l}\text { MNL } \\
\text { Model } 9\end{array}$ & $\begin{array}{l}\text { NL } \\
\text { Model } 10\end{array}$ & $\begin{array}{l}\text { RPL } \\
\text { Model } 11\end{array}$ \\
\hline Opt-out ASC & $\begin{array}{l}0.6626 * \\
(0.3942) \\
{[2.6752 * * *]}\end{array}$ & - & $\begin{array}{l}0.2729 \\
(0.4130) \\
{[2.2787 * * *]}\end{array}$ \\
\hline Price & $\begin{array}{l}-0.0074 * * * \\
(0.0012)\end{array}$ & $\begin{array}{l}-0.0052 * * * \\
(0.0007)\end{array}$ & $\begin{array}{l}-0.0111^{* * *} \\
(0.0015) \\
{[0.0053 * * *]}\end{array}$ \\
\hline Price $\times \mathrm{Inc}_{2}$ & $\begin{array}{l}0.0027 * * * \\
(0.0012)\end{array}$ & $\begin{array}{l}0.0021 * * * \\
(0.0005)\end{array}$ & $\begin{array}{l}0.0034 * * \\
(0.0014) \\
{[0.0020 *]}\end{array}$ \\
\hline Price $\times \mathrm{Inc}_{3}$ & $\begin{array}{l}0.0032 * * * \\
(0.0015)\end{array}$ & $\begin{array}{l}0.0033^{* * *} \\
(0.0006)\end{array}$ & $\begin{array}{l}0.0060 * * * \\
(0.0016) \\
{[0.0032]}\end{array}$ \\
\hline Eff & $\begin{array}{l}0.0826 * * * \\
(0.0062)\end{array}$ & $\begin{array}{l}0.0470 * * * \\
(0.0056)\end{array}$ & $\begin{array}{l}0.1109 * * * \\
(0.0097) \\
{[0.0457 * * *]}\end{array}$ \\
\hline Side & $\begin{array}{l}-0.0379 * * * \\
(0.0042)\end{array}$ & $\begin{array}{l}-0.0261 * * * \\
(0.0046)\end{array}$ & $\begin{array}{l}-0.0582 * * * \\
(0.0066) \\
{[0.0311 * * *]}\end{array}$ \\
\hline Weight & $\begin{array}{l}0.8116^{* * *} \\
(0.1483)\end{array}$ & $\begin{array}{l}0.5461 * * * \\
(0.1253)\end{array}$ & $\begin{array}{l}1.1101 * * * \\
(0.2331) \\
{[1.5877 * * *]}\end{array}$ \\
\hline Weight $\times \mathrm{Bmi}_{2}$ & $\begin{array}{l}0.3507 \\
(0.2189)\end{array}$ & $\begin{array}{l}0.1124 \\
(0.1342)\end{array}$ & $\begin{array}{l}0.0996 \\
(0.4132) \\
{[1.5815 * * *]}\end{array}$ \\
\hline Avail & $\begin{array}{l}0.0437 \\
(0.1174)\end{array}$ & $\begin{array}{l}0.0518 \\
(0.0794)\end{array}$ & $\begin{array}{l}0.2088 \\
(0.3822) \\
{[0.3822]}\end{array}$ \\
\hline \multicolumn{4}{|c|}{ Opt-out choice (NL only) } \\
\hline Years_sm & & $\begin{array}{l}0.0142 * * * \\
(0.0053)\end{array}$ & \\
\hline Help & & $\begin{array}{l}-0.1074 \\
(0.1509)\end{array}$ & \\
\hline Gender & & $\begin{array}{l}-0.0678 \\
(0.1340)\end{array}$ & \\
\hline Anx & & $\begin{array}{l}0.4791 * \\
(0.2640)\end{array}$ & \\
\hline $\mathrm{Sec}$ & & $\begin{array}{l}0.0999 \\
(0.1544)\end{array}$ & \\
\hline Sup & & $\begin{array}{l}-0.3342 * \\
(0.1982)\end{array}$ & \\
\hline Child & & $\begin{array}{l}-0.1041 \\
(0.1443)\end{array}$ & \\
\hline IV parameter & & $0.7171 * * *(0.1131)$ & \\
\hline $\mathrm{N}$ & 1,048 & 1,048 & 1,048 \\
\hline AIC & $1,517.5$ & $1,850.8$ & $1,450.9$ \\
\hline $\mathrm{BIC}$ & $1,578.2$ & $1,948.1$ & $1,560.3$ \\
\hline
\end{tabular}

Table 6 continued

\begin{tabular}{llll}
\hline Utility function & MNL & NL & RPL \\
& Model 9 & Model 10 & Model 11 \\
\hline 11 & -748.7 & -909.4 & -707.5 \\
\hline
\end{tabular}

In the MNL and RPL models, the opt-out option is defined with specific values for the attributes. In the NL model, the opt-out option has no associated attribute value. The MNL model includes a random opt-out ASC (normally distributed). All coefficients in Model 11 are assumed to be normally distributed. Standard errors in parentheses. Standard deviation of random coefficients in brackets

* Significant at $1 \%$

** Significant at $5 \%$

*** Significant at $10 \%$

following characteristics: $50 \%$ efficacy, $10 \%$ prevalence of minor side effects, attenuation of weight gain and restricted availability $(45 \times 14.6-10 \times 8.9+174.9=742.9)$. We then multiply this amount by 0.54 (i.e., 1 minus the estimated proportion of non-demanders). We obtain an incremental value of the improved hypothetical smoking cessation treatment over cold turkey of CHF 400. It is worth noting that we make the conservative assumption that the treatment has a value of zero for all nondemanders, as in Busch et al. [29].

From the estimated RPL models, it is possible to obtain individual-specific values for each coefficient conditional on the choice actually made and the value of the attributes $[50,57]$. We exploit this information to plot distributions of marginal WTP for each attribute (Fig. 2) in order to illustrate the importance of preference heterogeneity.

\section{Discussion}

We used a discrete choice experiment to assess smokers' preferences for hypothetical smoking cessation medications described with five attributes: the price of a complete treatment, the efficacy measured in terms of the probability of becoming a successful long-term quitter, the occurrence of minor side effects, whether the drug prevents weight gain associated with smoking cessation and whether the product is available over-the-counter. Such treatments primarily act by reducing the withdrawal symptoms of smoking cessation, therefore leading to increased success rates amongst users compared to cold turkey quitters. However, currently available products are costly, they are not yet reimbursed by social health insurance, they cause frequent minor side effects and they are not available over-the-counter.

Our results clearly show that there is potential demand for improved smoking cessation medications. Even if a considerable proportion of smokers who express interest in 
Table 7 Marginal WTP estimates

\begin{tabular}{lllll}
\hline Attribute & Model 1 & Model 3 & Model 4 & Model 6 \\
\hline Eff & $12.3(10.8 ; 14.1)$ & $16.2(12.7 ; 21.5)$ & $13.0(10.5 ; 16.8)$ & $14.6(11.2 ; 19.6)$ \\
Side & $-8.1(-10.6 ;-6.2)$ & $-7.4(-10.0 ;-5.4)$ & $-7.6(-10.4 ;-5.5)$ & $-8.9(-12.2 ;-6.4)$ \\
Weight & $170.9(125.1 ; 221.8)$ & $184.0(133.8 ; 252.9)$ & $164.8(115.4 ; 224.8)$ & $174.9(121.4 ; 246.4)$ \\
Avail & $0(-)$ & $0(-)$ & $0(-)$ & $0(-)$ \\
\hline
\end{tabular}

95\% Krinsky-Robb confidence intervals in brackets

\section{Efficacy}

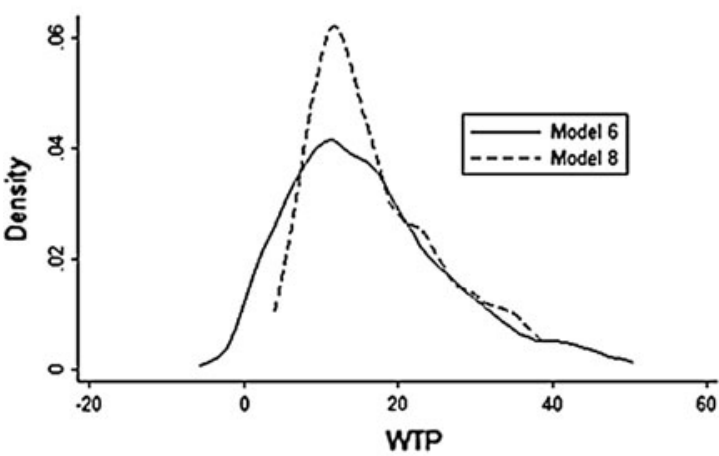

Prevention of weight gain

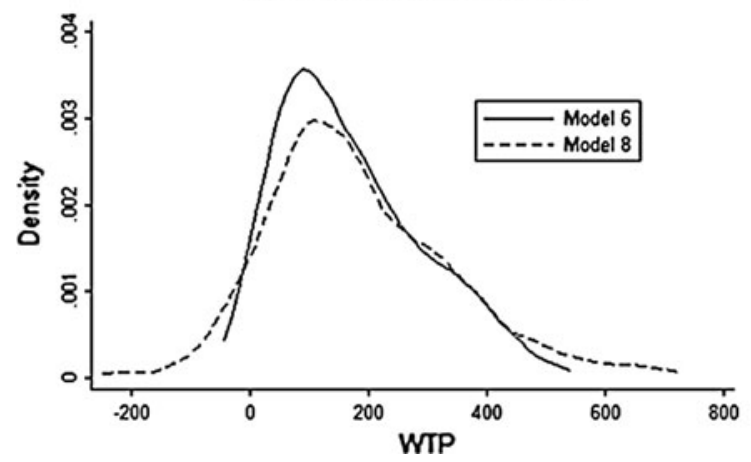

Side effects

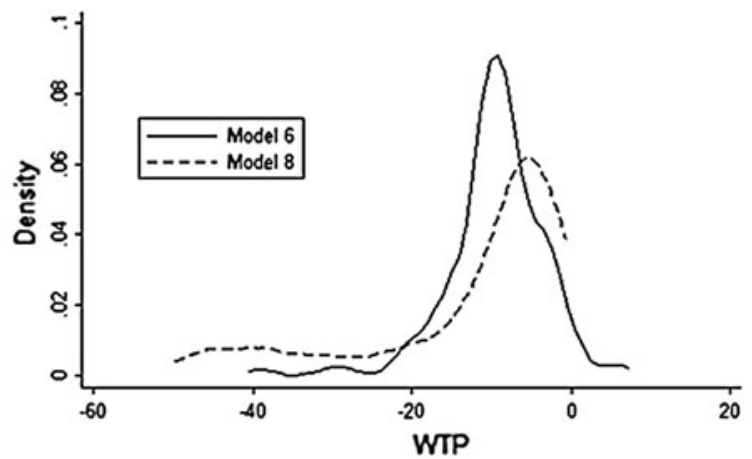

Availability

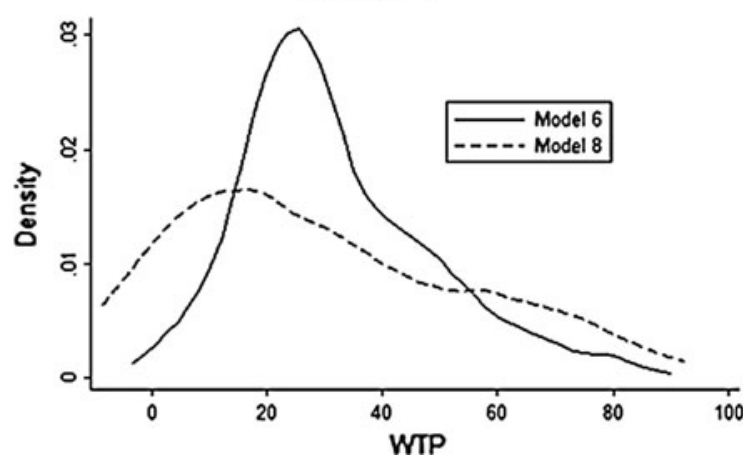

Fig. 2 Preference heterogeneity—WTP distributions

Table 8 Marginal WTP estimates by income group

\begin{tabular}{lcrr}
\hline Attribute & \multicolumn{2}{l}{ Income groups (CHF) } & \\
\cline { 2 - 4 } & $<4,500$ & $4,500-8,500$ & $>8,500$ \\
\hline Eff & $8.6(6.4 ; 12.5)$ & $14.8(11.4 ; 20.4)$ & $22.6(14.5 ; 45.8)$ \\
Side & $-5.3(-7.8 ;-3.7)$ & $-9.0(-12.8 ;-6.4)$ & $-13.7(-28.6 ;-8.4)$ \\
Weight (individuals with bmi $<=25)$ & $117.8(76.4 ; 182.0)$ & $201.9(132.9 ; 296.7)$ & $307.8(182.7 ; 610.4)$ \\
Weight (individuals with bmi $>25)$ & $123.4(76.2 ; 196.8)$ & $211.5(137.4 ; 318.4)$ & $322.4(179.0 ; 668.1)$
\end{tabular}

95\% Krinsky-Robb confidence intervals in brackets. Estimated coefficients and variance-covariance matrix from the RPL model with interactions used (Model 11). WTP for Avail not reported (the associated coefficient is not significant)

quitting are not willing to purchase such medications (optout rate of $46 \%$ ), individuals are willing to pay significant amounts for ameliorations of the relevant attributes. In line with the findings of Busch et al. [29] and Paterson et al. [30], we find that the probability of success is a fundamental characteristic. Individuals are willing to pay 
approximately $\mathrm{CHF} 12-16$ for a $1 \%$ point increase in the long-term success rate. This result indicates that the perceived net benefits of quitting are important, at least for demanders. Potential minor side effects, such as dry mouth or nausea, for instance, dampen usage and are thus negatively valued. A $1 \%$ point reduction in the probability of experiencing minor side effects is valued at around CHF 8. A striking figure is the substantial value (between CHF 160 and CHF 180, depending on the specification) that smokers attach to the fact that the drug contains an active ingredient that prevents cessation-related weight gain. This immediate cost of smoking cessation seems to play a major role in the decision to quit. Broader usage could therefore be reached through lower out-of-pocket price and greater efficacy. Secondary aspects such as side effects and weight gain should also be taken into consideration. Coverage of such treatments by the basic health insurance plan, or a subsidy targeted at the most deprived smokers, whose average rates of successful cessation are significantly lower than those of the rest of the population, are some of the possible policy options that are likely to lead to higher smoking cessation rates.

Results also show that opting out is influenced by several individual characteristics. Longer-term smokers and individuals reporting frequent anxiety are more likely to opt out, whereas individuals with higher education and with children in the household are less likely to opt out. Even current smokers who previously used a smoking cessation support (i.e., unsuccessful quitters) are less likely to opt out. This may indicate that they better perceive the potential benefits of using such products or simply that they have particular underlying characteristics that influence their choice and that are not altered by previous experience with the good. From a methodological point of view, we show the limitations of the simple multinomial logit model and therefore the importance of using more sophisticated models to study data from a discrete choice experiment. The nested logit models provide interesting insights in the opt-out decision and taking unobserved heterogeneity into account using the random parameter logit approach significantly improves the models.

However, this study has notable limitations. First, the respondents did not stem from a random national sample, and the sample is not very large $(N=131)$; their preferences may therefore not be representative of those of the general Swiss population of smokers. In addition, on the basis of existing literature, it is not possible to rule the validity of an analysis of preference heterogeneity with this sample size. Second, the use of a stated preference method raises the issue of hypothetical bias. However, the method provides many insights about the determinants of choice and allows for the capturing of the effects of features that are simply not available on the market or that do not vary enough in current alternatives. It could be useful to use real market data about smoking cessation medication sales and merge them with stated preference data resulting from a DCE. This would combine the advantages of both methodologies, i.e., the market equilibrium assessment (market data) with the analysis of trade-offs between attributes (DCE data). Third, we must keep in mind that, as explained in Kjaer et al. [58], the fact that price is always placed as the first attribute in the choice sets could have led to an overestimation of the WTP estimates.

It is important to keep in mind that we focus here only on the preferences of potential consumers. A number of other agents are involved in the smoking cessation drug market, including pharmaceutical companies that have incentives to promote their products, general practitioners that have a central influence in delivering the right to purchase (at least for drugs that are not sold OTC), and also public health authorities, who play a role in increasing the perceived benefits of smoking cessation and in deciding drug reimbursements. According to the 2007/2008 Swiss Tobacco Survey results, almost $80 \%$ of all smokers have already discussed tobacco use with their general practitioner or dentist. One in five smokers in Switzerland has been proposed cessation support from their physician; a vast majority of advice was focused on NRTs (35\%) and books $(25 \%)$. Zyban ${ }^{\circledR}$ and Champix ${ }^{\circledR}$ were proposed only 8 and $5 \%$ of the time, respectively [59]. A potential extension of this research would be to study physicians' behaviour and incentives to prescribe such drugs and to assess what part of the decision is induced by potential quitters and what part is caused by the physician. The implications of a possible reimbursement contingent on successful cessation that could provide the best incentive for people to engage in quitting behaviour should also be analysed in the Swiss setting. Other extensions would be to analyse preferences using a labelled DCE as Paterson et al. [30] did, including Champix ${ }^{\circledR}$ (varenicline) as an additional alternative, and to apply Latent Class Models to further investigate preference heterogeneity [60].

\section{Appendix}

See Table 9. 
Table 9 Example of choice set

\begin{tabular}{|c|c|c|c|}
\hline Attributes & Medication A & Medication B & Neither \\
\hline $\begin{array}{l}\text { Price } \\
\text { Price of the } \\
\text { comprehensive } \\
\text { treatment in } \mathrm{CHF}\end{array}$ & $500 \mathrm{CHF}$ & $200 \mathrm{CHF}$ & \\
\hline $\begin{array}{l}\text { Efficacy } \\
\% \text { of quitters who } \\
\text { still do not smoke } \\
1 \text { year after the } \\
\text { treatment and do } \\
\text { not want to restart } \\
\text { at all }\end{array}$ & $25 \%$ & $40 \%$ & \\
\hline $\begin{array}{l}\text { Side effects } \\
\% \text { of patients who } \\
\text { encounter minor } \\
\text { side effects } \\
\text { (insomnia, dry } \\
\text { mouth and so forth) }\end{array}$ & $30 \%$ & $50 \%$ & \\
\hline $\begin{array}{l}\text { Does the medication } \\
\text { prevent weight gain } \\
\text { associated with } \\
\text { smoking cessation? }\end{array}$ & No & Yes & \\
\hline Availability & $\begin{array}{l}\text { Over-the- } \\
\text { counter }\end{array}$ & $\begin{array}{l}\text { Medical } \\
\text { prescription }\end{array}$ & \\
\hline Your choice & & & \\
\hline
\end{tabular}

\section{References}

1. Swiss Federal Statistical Office: Les décès dus au Tabac en Suisse. Estimation Pour les Années Entre 1995 et 2007. Swiss Federal Statistical Office, Neuchâtel (2009)

2. Keller, R., Radtke, T., Krebs, H., Hornung, R.: Der Tabakkonsum der Schweizer Wohnbevölkerung in den Jahren 2001 bis 2009. Tabakmonitoring-Schweizerische Umfrage zum Tabakkonsum. Psychologisches Institut der Universität Zürich. Sozial- und Gesundheitspsychologie, Zürich (2010)

3. Joosens, L., Raw, M.: The tobacco control scale (TCS): a new scale to measure country activity. Tob Control 15, 247-253 (2006)

4. Fiore, M.: Treating Tobacco Use and Dependance, Public Health Service Clinical Practice Guideline. US Department of Health and Human Services, Rockville, MD (2000)

5. Wu, P., Wilson, K., Dimoulas, P., Mills, E.J.: Effectiveness of smoking cessation therapies: a systematic review and metaanalysis. BMC Public Health 6, 300 (2006)

6. Compendium suisse des médicaments. Documed AG, Basel (2002)

7. Gonzales, D., Rennard, S.I., Nides, M., Oncken, C., Azoulay, S., Billing, C.B., Watsky, E.J., Gong, J., Williams, K.E., Reeves, K.R.: Varenicline, an $\alpha 4 \beta 2$ nicotinic acetylcholine receptor partial agonist, vs sustained-released bupropion and placebo for smoking cessation. JAMA 296, 47-55 (2006)

8. Berchi, C., Dupuid, J.-M., Launoy, G.: The reasons of general practitioners for promoting colorectal cancer mass screening in France. Eur. J. Health Econ. 7, 91-98 (2006)
9. Brau, R., Bruni, M.L.: Eliciting the demand for long-term care coverage: a discrete choice modelling analysis. Health Econ. 17, 411-433 (2008)

10. Ryan, M., Netten, A., Skatun, D., Smith, P.: Using discrete choice experiments to estimate a preference-based measure of outcome-An application to social care for older people. J. Health Econ. 25, 927-944 (2006)

11. Zweifel, P., Telser, H., Vaterlaus, S.: Consumer resistance against regulation: the case of health care. J. Regul. Econ. 29, 319-332 (2005)

12. Kerssens, J.J., Groenewegen, P.: Consumer preferences in social health insurance. Eur. J. Health Econ. 29, 319-332 (2005)

13. Ryan, M., Hughes, J.: Using conjoint analysis to assess women's preferences for miscarriage management. Health Econ. 6, 261-273 (1997)

14. Hall, J., Kenny, P., King, M., Louviere, J., Viney, R., Yeoh, A.: Using stated preference discrete choice modelling to evaluate the introduction of varicella vaccination. Health Econ. 11, 457-465 (2002)

15. Aristides, M., Weston, A.R., FitzGerald, P., Reun, C.L., Maniadakis, N.: Patient preference and willingness-to-pay for Humalog Mix25 relative to Humulin 30/70: A multicountry application of a discrete choice experiment. Value Health 7, 442-454 (2004)

16. Mark, T.L., Swait, J.: Using stated preference modeling to forecast the effect of medication attributes on prescriptions of alcoholism medications. Value Health 6, 474-482 (2003)

17. Marshall, D.A., Johnson, F.R., Phillips, K.A., Marshall, J.K., Thabane, L., Kulin, N.A.: Measuring patient preferences for colorectal cancer screening using a choice-format survey. Value Health 10, 415-430 (2007)

18. Roux, L., Ubach, C., Cam, : Valuing the benefits of weight loss programs: An application of the discrete choice experiment. Obes. Res. 12, 1342-1351 (2004)

19. Bryan, S., Buxton, M., Sheldon, R., Grant, A.: Magnetic resonance imaging for the investigation of knee injuries: an investigation of preferences. Health Econ. 7, 595-603 (1998)

20. Watson, V., Ryan, M., Brown, C.T., Barnett, G., Ellis, B.W., Emberton, M.: Eliciting prefenrences for drug treatment of lower urinary tract symptoms associated with benign prostatic hyperplasia. J. Urol. 172, 2321-2325 (2004)

21. Bertram, M.Y., Lim, S.S., Wallace, A.L., Vos, T.: Costs and benefits of smoking cessation aids: making a case for public reimbursement of nicotine replacement therapy in Australia. Tob. Control. 16, 255-260 (2007)

22. Cornuz, J., Gilbert, A., Pinget, C., McDonald, P., Slama, K., Salto, E., Paccaud, F.: Cost-effectiveness of pharmacotherapies for nicotine dependence in primary care settings: a multinational comparison. Tob. Control. 15, 152-159 (2006)

23. Hall, S.M., Lightwood, J.M., Humfleet, G.L., Bostrom, A., Reus, V.I., Munoz, R.: Cost-effectiveness of Bupropion, Nortriptyline, and psychological intervention in smoking cessation. J. Behav. Health Ser R. 32, 381-392 (2005)

24. Warner, K.: Cost-effectiveness of smoking-cessation therapiesinterpretation of the evidence and implications for coverage. Pharmacoeconomics 11, 538-549 (1997)

25. Tauras, J.A., Chaloupka, F.J.: The demand for nicotine replacement therapies. Nicotine Tob. Res. 5, 237-243 (2003)

26. Keeler, T.E., Hu, T.-W., Keith, A., Manning, R., Marciniak, M., Ong, M., Sung, H.-Y.: The benefits of switching smoking cessation drugs to over-the-counter status. Health Econ. 11, 389-402 (2002)

27. Halpin, H.A., McMenamin, S.B., Shade, S.B.: The demand for health insurance coverage for tobacco dependence treatments: Support for a benefit mandate and willigness to pay. Nicotine Tob. Res. 9, 1269-1276 (2007) 
28. Avery, R., Kenkel, D., Lillard, D.R., Mathios, A.: Private profits and public health: does advertising of smoking cessation products encourage smokers to quit? J. Polit. Econ. 115, 447-481 (2007)

29. Busch, S.H., Falba, T.A., Duchovny, N., Jofre-Bonet, M., O'Malley, S.S., Sindelar, J.L.: Value to smokers of improved cessation products: Evidence from a willingness-to-pay survey. Nicotine Tob. Res. 6, 631-639 (2004)

30. Paterson, R.W., Boyle, K.J., Parmeter, C.F., Neumann, J.E., Civita, P.D.: Heterogeneity in preferences for smoking cessation. Health Econ. 17, 1363-1377 (2008)

31. Hensher, D.A., Rose, J.M., Greene, W.H.: Applied Choice Analysis. Cambridge University Press, Cambridge (2005)

32. Lancaster, K.J.: A new approach to consumer theory. J. Polit. Econ. 74, 132-157 (1966)

33. McFadden, D.: Econometric models of probalistic choice. In: Manski, C., McFadden, D. (eds.) Structural Analysis of Discrete Choice Data with Economic Applications, pp. 422-434. MIT Press, Boston (1981)

34. Ryan, M., Gerard, K., Amaya-Amaya, M.: Using discrete choice experiments to value health and health care. Springer, Dordrecht (2008)

35. Peters, M.J., Morgan, L.C.: The parmacotherapy of smoking cessation. Med. J. Aust. 176, 486-490 (2002)

36. Henningfield, J.E., Fant, R.V., Buchalter, A.R., Stitzer, M.L.: Pharmacotherapy for nicotine dependance. Cancer J. Clin. 55, 281-299 (2005)

37. Jorenby, D.E., Hays, J.T., Rigotti, N.A., Azoulay, S., Watsky, E.J., Williams, K.E., Billing, C.B., Gong, J., Reeves, K.R.: Efficacy of varenicline, an $\alpha 4 \beta 2$ nicotinic acetylcholine receptor partial agonist, vs placebo or sustained-release bupropion for smoking cessation. JAMA 296, 56-63 (2006)

38. McEwen, A., West, R., Owen, L.: GP prescribing of nicotine replacement and bupropion to aid smoking cessation in England and Wales. Addiction 99, 1470-1474 (2004)

39. Froom, P., Melamed, S., Benbassat, J.: Smoking cessation and weight gain. J. Fam. Pract. 46, 460-464 (1998)

40. Klesges, R., Winders, S., Meyers, A., Eck, L., Ward, K., Hultquist, C.: How much weight gain occurs following smoking cessation? A comparison of weight gain using both continuous and point prevalence abstinence. J. Consult. Clin. Psych. 65, 286-291 (1997)

41. Williamson, D., Madans, J., Anda, R., Kleinman, J., Giovino, G., Byers, T.: Smoking cessation and severity of weight gain in a national cohort. New Engl. J. Med. 324, 739-745 (1991)

42. Meyers, A.W., Klesges, R.C., Winders, S.E., Ward, K.D., Peterson, B.A., Eck, L.H.: Are weight concerns predictive of smoking cessation? A prospective analysis. J. Consult Clin. Psych. 65, 448-452 (1997)

43. Ryan, M., Skatun, D.: Modelling non-demanders in choice experiments. Health Econ. 13, 397-402 (2004)
44. Sloane, N.J.A.: A library of orthogonal arrays. http://www.research.att.com/ njas/oadir/ (2007). Accessed Dec 2007

45. Street, D.J., Burgess, L.: The construction of optimal stated choice experiments. Wiley, Hoboken (2007)

46. Burgess, L.: Discrete choice experiments (computer software), Department of Mathematical Sciences, University of Technology, Sydney, http://crsu.science.uts.edu.au/choice/ (2007). Accessed Jan 2011

47. Lancsar, E., Louviere, J.: Deleting 'irrational' responses from discrete choice experiments: a case of investigating or imposing preferences. Health Econ. 15, 797-811 (2006)

48. Miguel, F.S., Ryan, M., Amaya-Amaya, M.: 'Irrational' stated preferences: a quantitative and qualitative investigation. Health Econ. 14, 307-322 (2005)

49. McFadden, D.: Conditional logit analysis of qualitative choice behavior. In: Zarembka, P. (ed.) Frontiers in Econometrics, pp. 105-142. Academic Press, New-York (1974)

50. Train, K.E.: Discrete choice methods with simulation. Cambridge University Press, Cambridge (2003)

51. Louviere, J.J., Hensher, D.A., Swait, J.D.: Stated Choice Methods. Cambridge University Press, Cambridge (2000)

52. Ryan, M., Major, K., Skatun, D.: Using discrete choice experiments to go beyond clinical outcomes when evaluating clinical practice. J. Eval. Clin. Pract. 11, 328-338 (2005)

53. Haefen, R.H.V., Massey, D.M., Adamowicz, W.: Serial nonparticipation in repeated discrete choice models. Am. J. Agr. Econ. 87, 1061-1076 (2005)

54. Hausman, J., McFadden, D.: Specification tests for the multinomial logit model. Econometrica 52, 1219-1240 (1984)

55. Hole, A.R.: A comparison of approaches to estimating confidence intervals for willingness to pay measures. Health Econ. 16, 827-840 (2007)

56. Krinsky, I., Robb, A.: On approximating the statistical properties of elasticities. Rev. Econ. Stat. 72, 189-190 (1986)

57. Hole, A.R.: Modelling heterogeneity in patients' preferences for the attributes of a general practitioner appointment. J. Health. Econ. 27, 1078-1094 (2008)

58. Kjaer, T., Bech, M., Gyrd-Hansen, D., Hart-Hansen, K.: Ordering effect and price sensitivity in discrete choice experiments: Need we worry. Health Econ. 15, 1217-1228 (2006)

59. Krebs, H., Keller, R., Radtke, T., Hornung, R.: Raucherberatung in der ärztlichen und zahnmedizinischen Praxis aus Sicht der Rauchenden und ehemals Rauchenden (Befragung 2009). Tabakmonitoring-Schweizerische Umfrage zum Tabakkonsum. Psychologisches Institut der Universität Zürich, Sozial- und Gesundheitspsychologie, Zürich (2010)

60. Mentzakis, E., Ryan, M., McNamee, P.: Using discrete choice experiment to value informal care tasks: exploring preference heterogeneity. Health Econ. (2010). doi:10.1002/hec.1656 